\title{
CLINICAL MEDICINE
}

\section{СЛУЧАЙ МНОГОЭТАПНОГО ЛЕЧЕНИЯ ОСТРОГО ПАНКРЕАТИТА С ИСПОЛЬЗОВАНИЕМ РАЗЛИЧНЫХ МИНИИНВАЗИВНЫХ МЕТОДИК}

\author{
С. Я. Ивануса ${ }^{1}$, М. В. Лазуткин ${ }^{1}$, Д. П. Шершень, ${ }^{1}$ А. В. Чеботарь ${ }^{1}$ \\ ${ }^{1}$ ФГБВОУ В0 «Военно-медицинская академия имени С. М. Кирова» МО РФ, г. Санкт-Петербург, Россия

\section{THE CASE OF THE MULTISTAGE TREATMENT OF ACUTE PANCREATITIS USING A VARIETY OF MINIMALLY INVASIVE TECHNIQUES}

\author{
S. Ya. Ivanusa ${ }^{1}$, M. V. Lazutkin ${ }^{1}$, D. P. Shershen ${ }^{1}$, A.V. Chebotar ${ }^{1}$ \\ ${ }^{1}$ S. M. Kirov Military Medical Academy of the Russian Defense Ministry, Saint Petersburg, Russia
}

\begin{abstract}
Резюме. Лечение острого панкреатита и его инфекционных осложнений является сложной задачей. Применение традиционных хирургических вмешательств для санации очагов панкреатогенной инфекции зачастую утяжеляет течение болезни, приводит к развитию послеоперационных осложнений, не улучшает результаты лечения. Напротив, применение миниинвазивных техник позволяет избежать дополнительной операционной травмы. Вниманию читателей представляется случай этапного лечения острого панкреатита и его гнойно-септических осложнений с применением малоинвазивных технологий (13 рис., 1 табл., библ.: 6 ист.).
\end{abstract}

Ключевые слова: миниинвазивные вмешательства, острый панкреатит, панкреонекроз.

Статья поступила в редакцию 30.09.2020 г.

\section{ВВЕДЕНИЕ}

Острый панкреатит (ОП) и его инфекционные осложнения являются одной из актуальнейших проблем в неотложной абдоминальной хирургии. Количество больных ОП постоянно увеличивается и составляет до 80 человек на 100000 населения $[1,4,5]$. По частоте причин госпитализаций в неотложной хирургии это заболевание занимает одно из лидирующих мест, уступая только острому аппендициту и острому холециститу $[1,4,5]$. ОП тяжелой степени встречается до $30 \%$ случаев. Летальность при данной форме заболевания может достигать 30\%, а при развитии инфекционных осложнений - $85 \%[2,3,5]$. Инфекционные осложнения развиваются у 30-70\% больных с ОП тяжелой степени и являются основным фактором летального исхода $[2,3,5]$.

\section{КЛИНИЧЕСКОЕ НАБЛЮДЕНИЕ}

Пациент М., 69 лет, поступил в клинику 21.09.2017 г. на первые сутки от начала заболевания. При клинико-инструментальном обследовании установлен предварительный диагноз: острый тяжелый панкреатит, оментобурсит (рис. 1).

Начато консервативное лечение согласно клиническим рекомендациям. В ходе динамического инструментального (УЗИ, КТ) контроля на 8-е сут выявлено формирование острого жидкостного
Summary. Treatment of acute pancreatitis and infectious complications is a complex multidisciplinary task. The use of traditional surgical procedures for the rehabilitation of foci of pancreatogenic infection often aggravates the course of the disease, leads to the development of postoperative complications, does not improve the results of treatment. On the contrary, the use of minimally invasive techniques avoids additional surgical injury. The case of stage treatment of acute pancreatitis and its purulent-septic complications with the use of minimally invasive technologies is presented to the readers ( 13 figs, 1 table, bibliography: 6 refs).

Key words: acute pancreatitis, mini-invasive interventions, pancreonecrosis.

Article received 30.09.2020.

скопления (ОЖС) в сальниковой сумке (рис. 2). На 13-е сут заболевания, 04.10.2017 г., появились признаки инфицирования ОЖС - повышение температуры тела до $38,5^{\circ} \mathrm{C}$, лейкоцитоз до 11,3 × 10\% /л, С-реактивный белок - 156 мг/л, что явилось показанием к оперативному вмешательству.

Под контролем эндосонографии 04.10.2017 г. выполнено эндоскопическое цистоназальное трансгастральное дренирование ОЖС сальниковой сумки с установкой цистоназального дренажа диаметром 5 Fr и цистогастрального дренажа типа double PigTail диаметром 7 Fr (рис. 3). Получено 200 мл жидкости бурого цвета, уровень амилазы в которой составил 16000 Ед/л. При бактериологическом исследовании отделяемого роста микроорганизмов не выявлено.

Для контроля функционирования установленных дренажей 06.10.2017 г. выполнена рентгенофистулография через цистоназальный дренаж. После неравномерного заполнения контрастом сальниковой сумки выявлено отсутствие контрастирования цистогастрального дренажа и поступления рентгеноконтрастного препарата в просвет желудка. Полученные данные свидетельствовали о неудовлетворительном дренировании ОЖС в связи с наличием в полости густого содержимого, секвестров и недостаточного диаметра цистогастрального дренажа (рис. 4). 
КАИНИЧЕСКАЯ МЕАИЦИНА

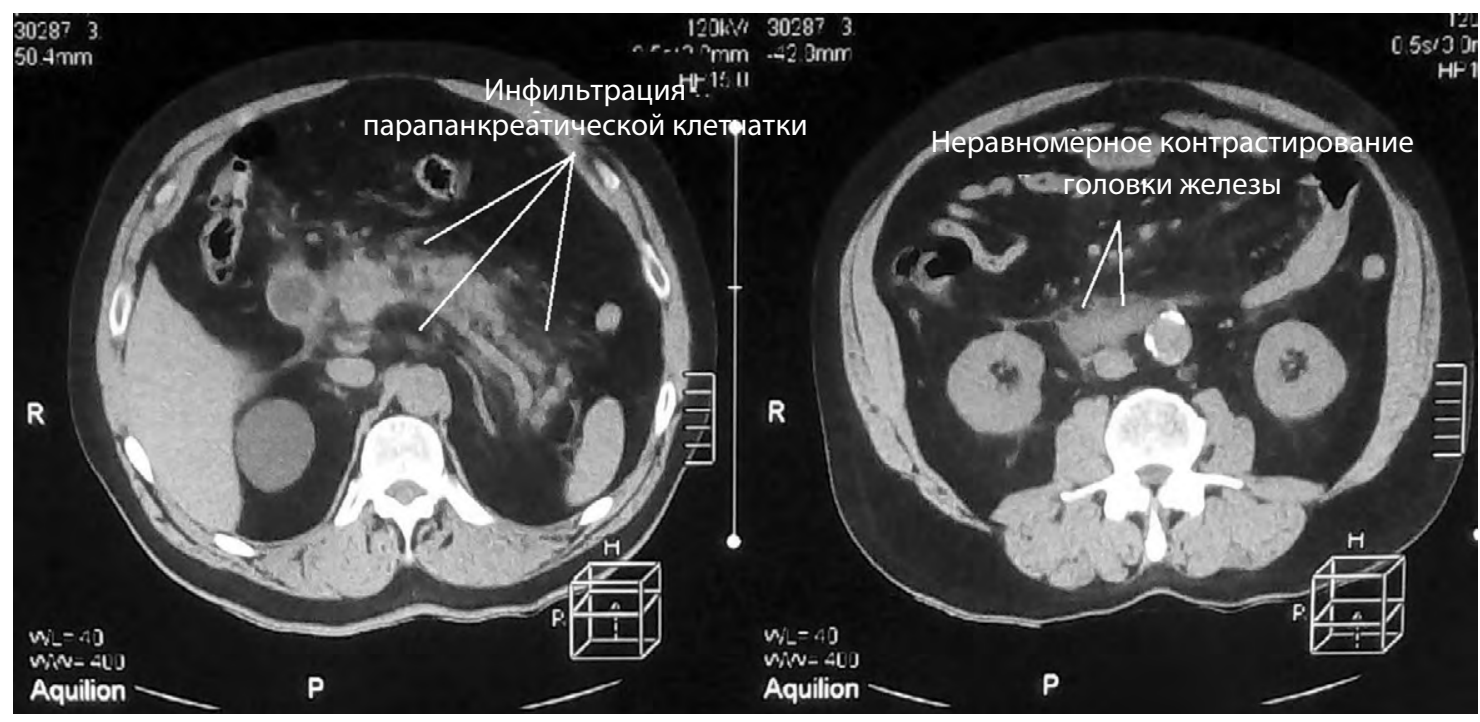

Рис. 1. КТ брюшной полости больного М. от 21.09.2017 г. (1-е сут болезни)

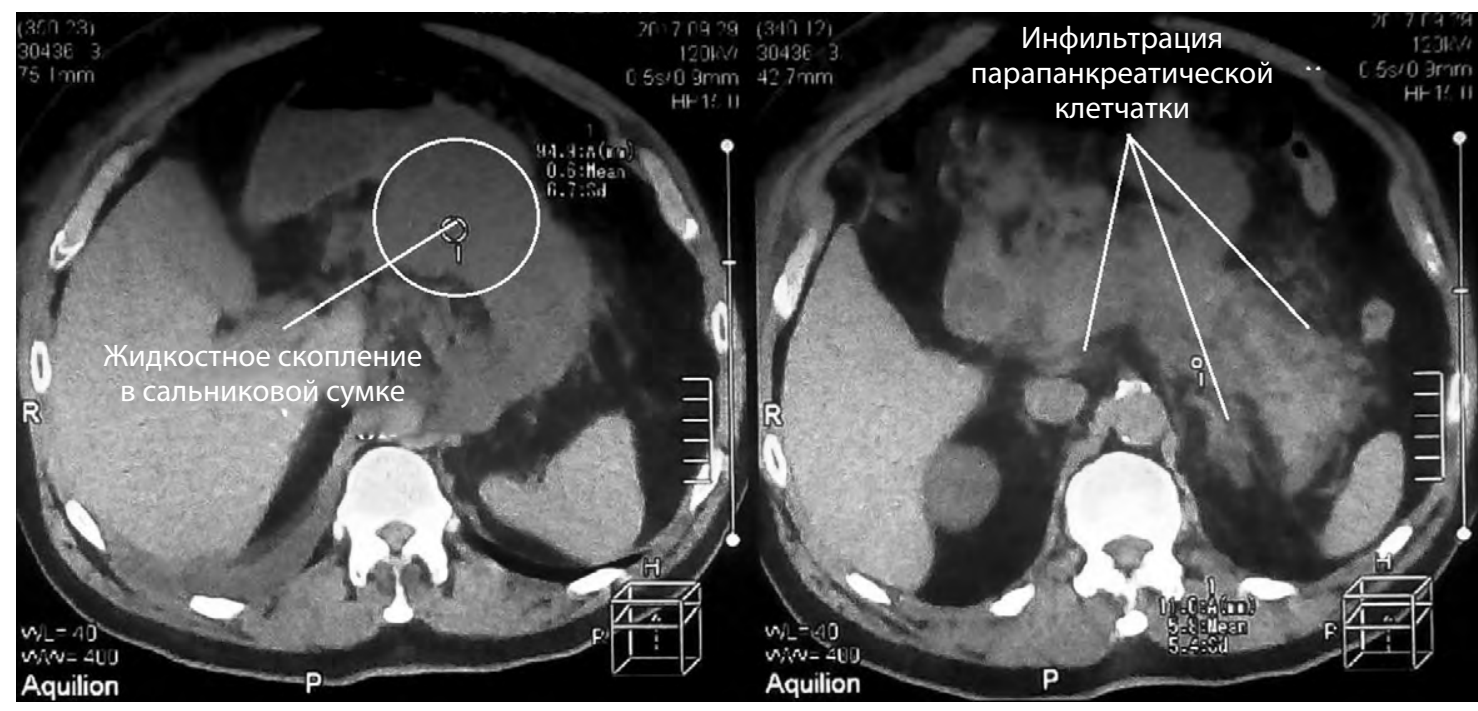

Рис. 2. КТ брюшной полости больного М. от 29.09.2017 г. (8-е сут болезни)

Принято решение о выполнении редренирования ОЖС с установкой дренажа большего диаметра. 06.10.2017 г. выполнена эндоскопическая установка цистогастрального саморасширяющегося стента-эндопротеза для псевдокист диаметром 12 мм (рис. 5 A, Б).

В послеоперационном периоде проводилось ежедневное промывание полости сальниковой сумки 0,05\%-ным раствором хлоргекседина биглюконата через цистоназальный дренаж. На фоне проводимого лечения отмечена нормализация температуры тела и лабораторных показателей. При рентгенофистулографии от 12.10.2017 г. выявлены значительное уменьшение размеров ОЖС сальниковой сумки, свободное поступление рентгеноконтрастного препарата в просвет желудка (рис. 5 В).

С 18.10.2017 г. (27-е сут болезни) больной стал предъявлять жалобы на повышение температу- ры тела до $38-38,5{ }^{\circ} \mathrm{C}$ в вечерние часы. В анализах крови отмечено увеличение числа лейкоцитов до $12,3 \times 10 \%$ л, уровня С-реактивного белка до 224,3 мг/л. При КТ живота от 19.10.2017 г. выявлено формирование жидкостного образования в корне брыжейки тонкой кишки, поперечной ободочной кишки, отграниченного тонкой капсулой неправильной формы размерами до 4,0 × 7,5 × 4,5 см с неоднородным содержимым (рис. 6).

На фоне лихорадки трехкратно выполнен посев крови на стерильность, роста микрофлоры не выявлено. Учитывая клинико-лабораторные изменения, а также данные компьютерной томографии, у пациента диагностирован абсцесс корня брыжейки тонкой кишки, что явилось показанием к выполнению оперативного вмешательства. Отсутствие акустического окна при ультразвуковом трансабдоминальном исследовании, расположение 


\section{CLINICAL MEDICINE}

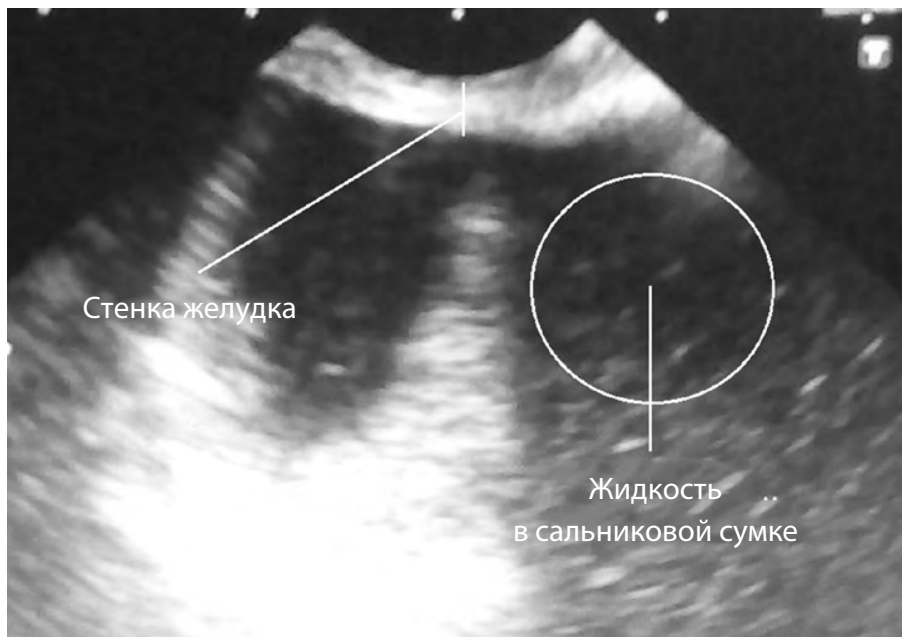

A

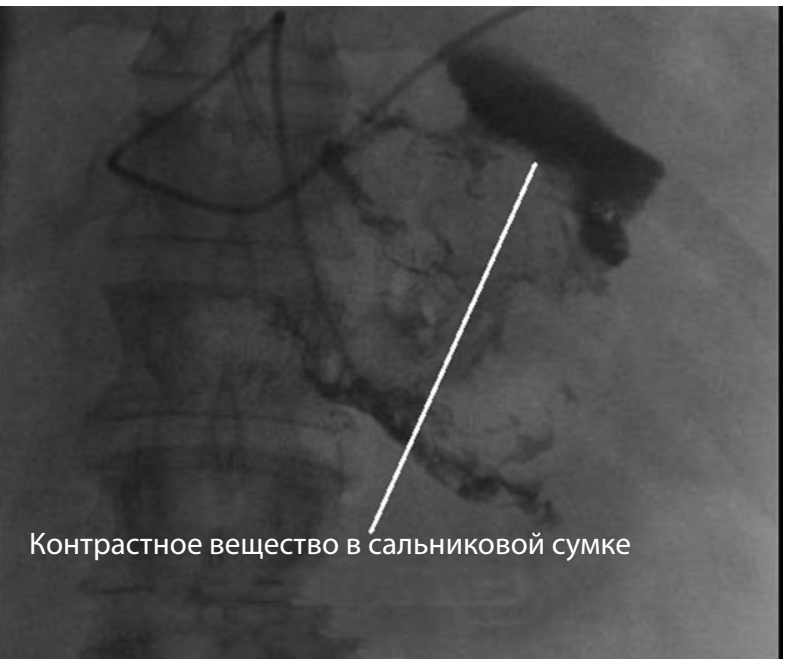

Б

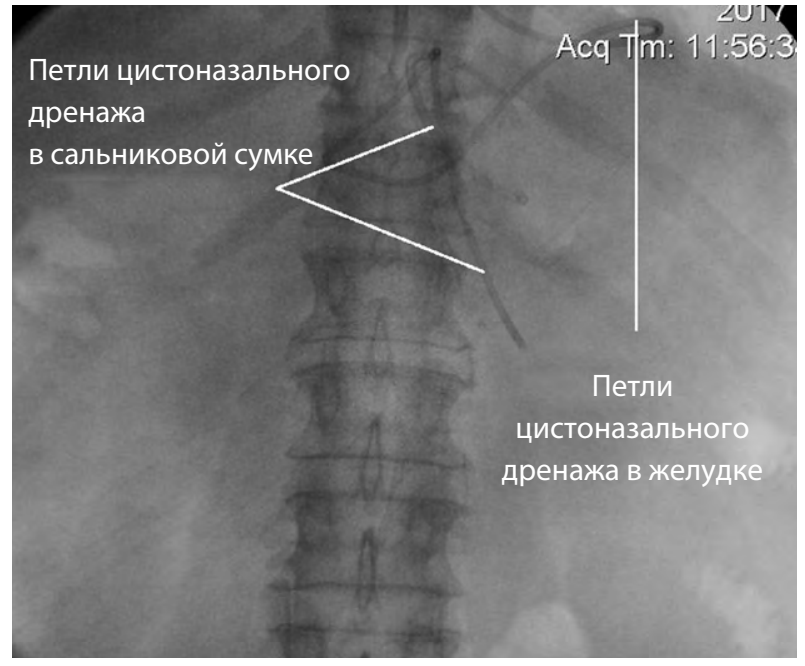

B

Рис. 3. Этапы цистоназального дренирования жидкостного скопления сальниковой сумки (13-е сут болезни). А - эндосонограмма жидкостного скопления сальниковой сумки; Б - цистоназальный дренаж в полости сальниковой сумки; В - интраоперационная фистулография

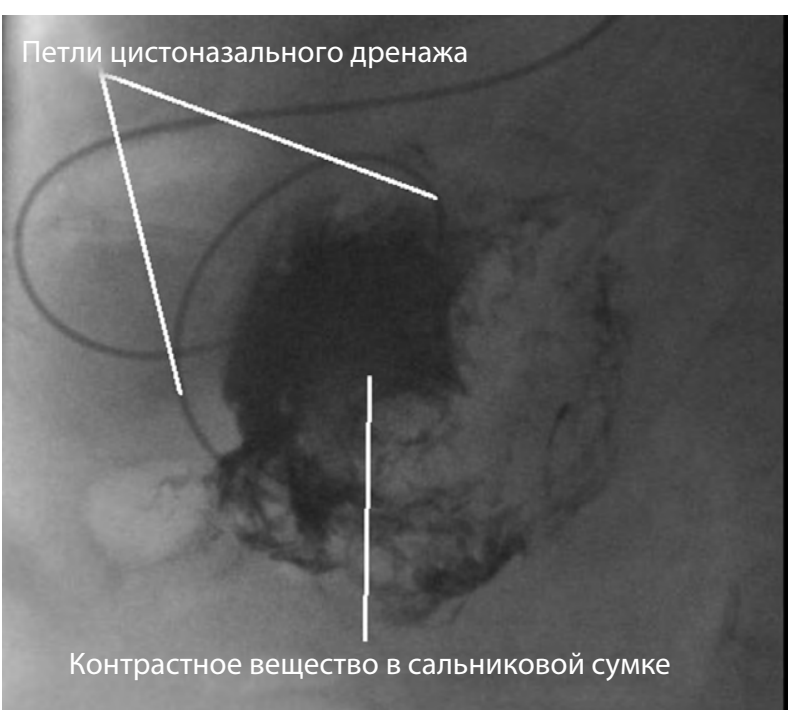

Рис. 4. Фистулограмма на 2-е сут после цистоназального дренирования ОЖС сальниковой сумки (14-е сут болезни) абсцесса позади брыжеечных сосудов определили невозможность выполнения чрескожного пункционного дренирования. 24.10.2017 г. выполнено лапароскопическое дренирование абсцесса области корня брыжейки тонкой кишки с использованием лапароскопического ультразвукового датчика. Получено 30 мл гноя белого цвета без запаха. Интраоперационно установлено, что полость абсцесса имеет вытянутую форму с двумя затеками, каждый из которых был дренирован отдельным дренажем (рис. 7). При бактериологическом исследовании гноя выделена монокультура Acinetobacter baumani, чувствительная к Ванкомицину.

В последующие сутки на фоне ежедневных промываний дренажей 0,05\% раствором хлоргекседина биглюконата отмечалась положительная динамика в состоянии пациента, снижение температуры тела до нормальных значений и С-реактивного белка до 190 мг/л. При КТ от 10.11.2017 г. отмечено умень- 


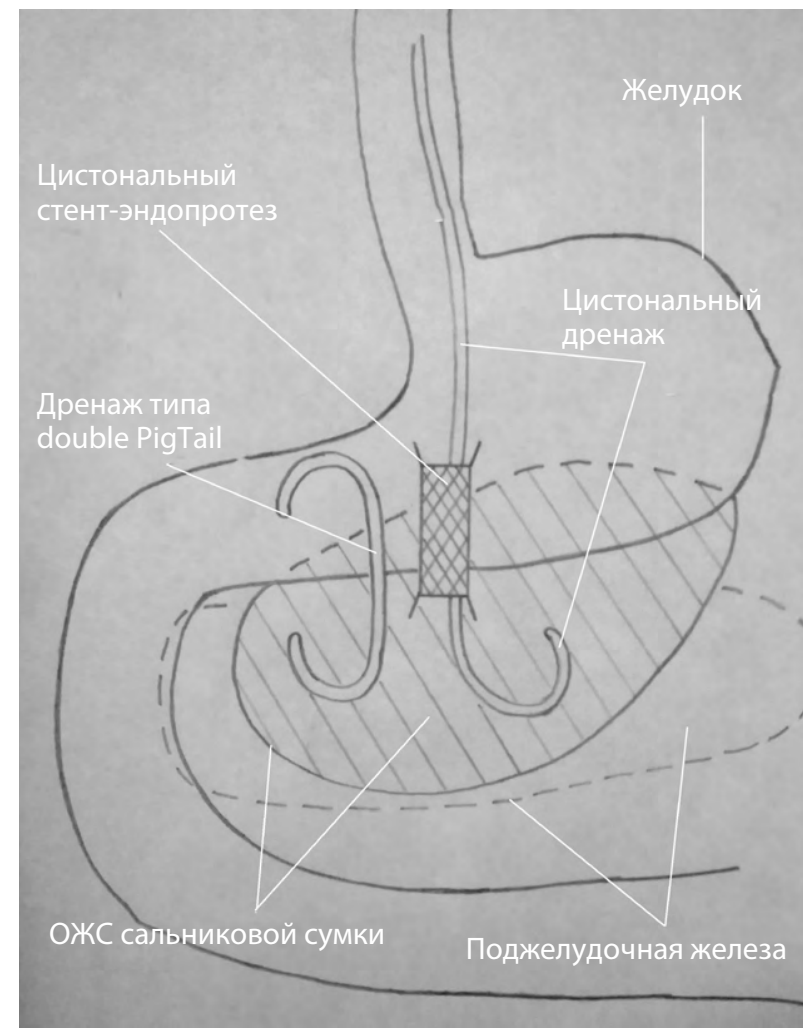

A

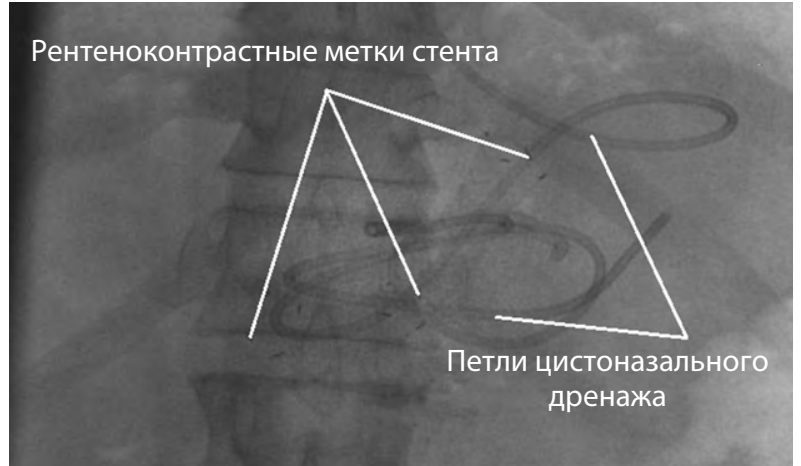

Б

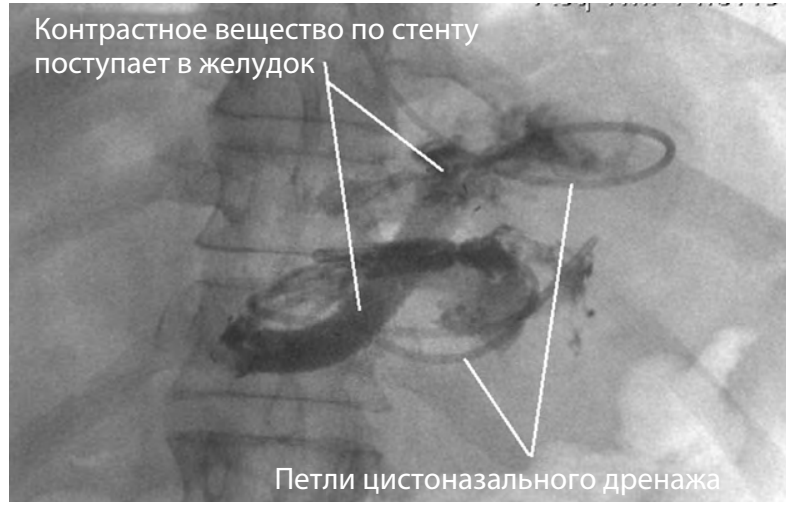

B

Рис. 5. Редренирование сальниковой сумки и контрольное рентгенконтрастное исследование (71-е сут болезни).

А - схема редренирования сальниковой сумки с установкой стента; Б - интраоперационная рентгенограмма; В - контрольная фистулография на 6-е сут после повторного дренирования ОЖС сальниковой сумки

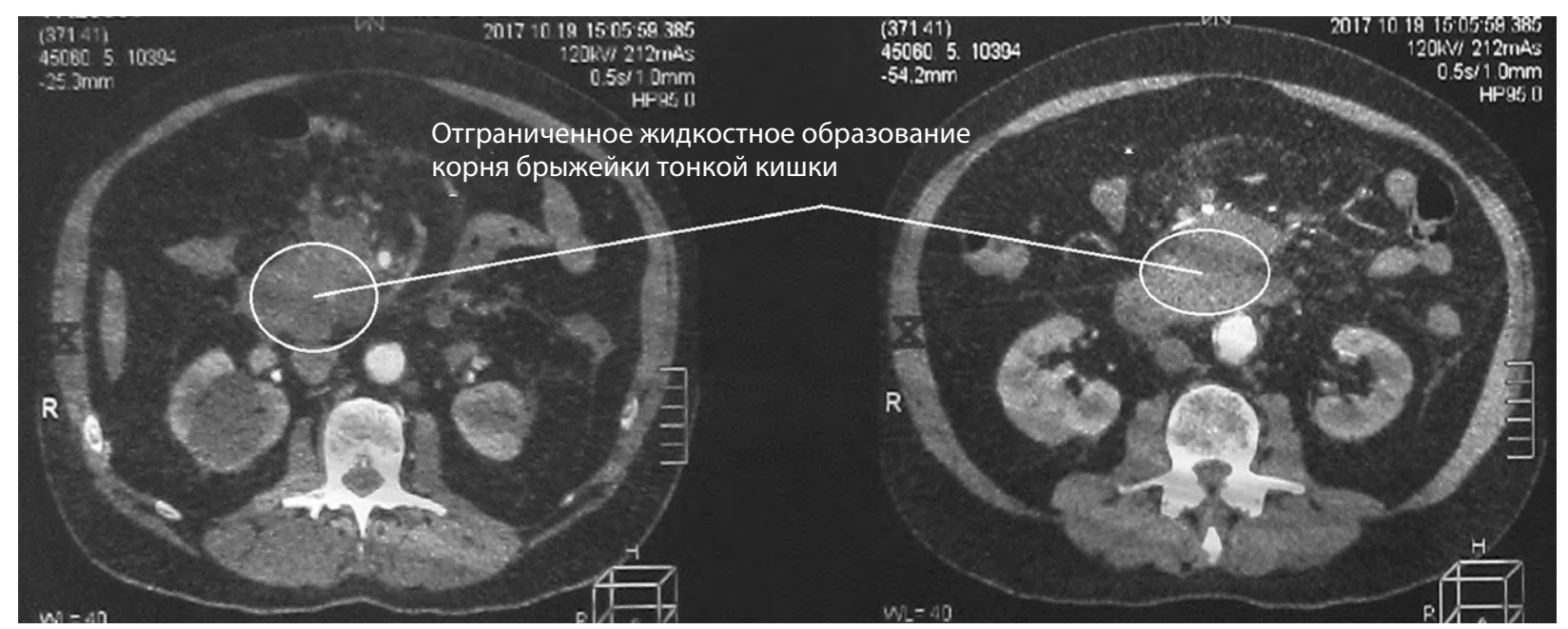

Рис. 6. Абсцесс забрюшинного пространства в области корня брыжейки тонкой кишки. КТ брюшной полости больного М. от 19.10.2018 г. (28-е сут болезни)

шение размеров полости абсцесса корня брыжейки тонкой кишки (рис. 8).

При контрольной фиброгастродуоденоскопии (ФГДС) от 15.11.2017 г. выявлено, что цистогастральный стент-эндопротез мигрировал в просвет желудка. В месте его установки сформи- ровалось свищевое отверстие диметром до 10 мм между желудком и сальниковой сумкой, в просвете которого визуализировался секвестр парапанкреатической клетчатки (рис. 9).

Выполнена эндоскопическая секвестрэктомия. С учетом возможности выполнения эндо- 


\section{CLINICAL MEDICINE}

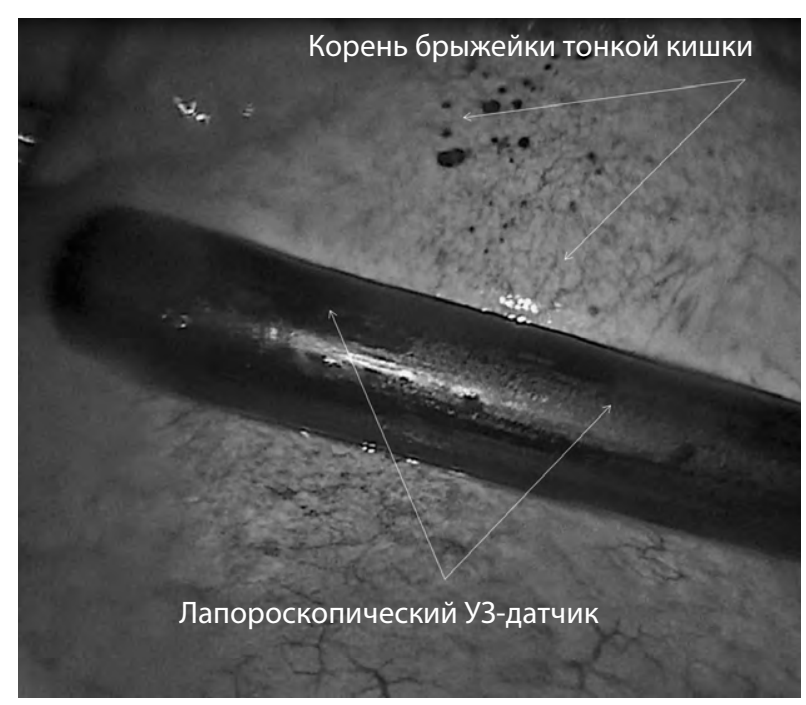

A

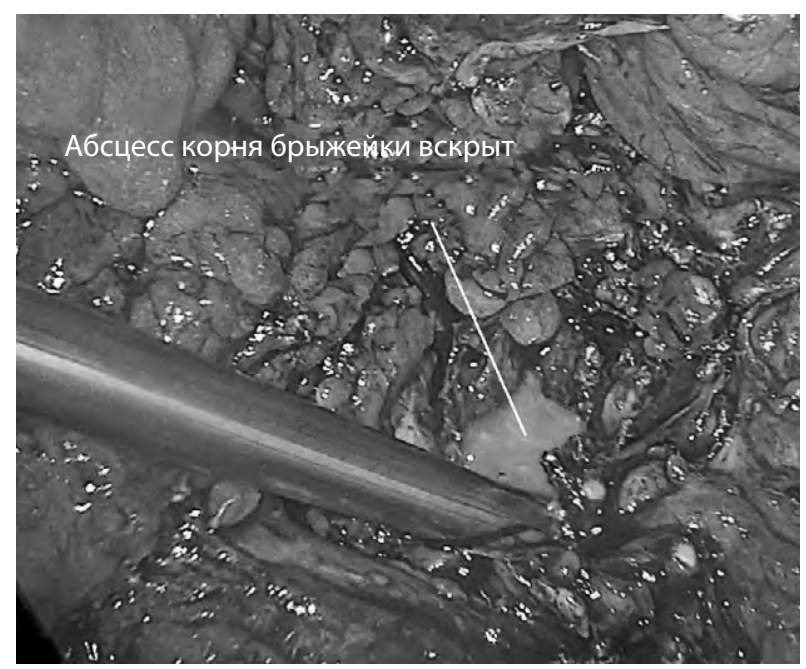

B

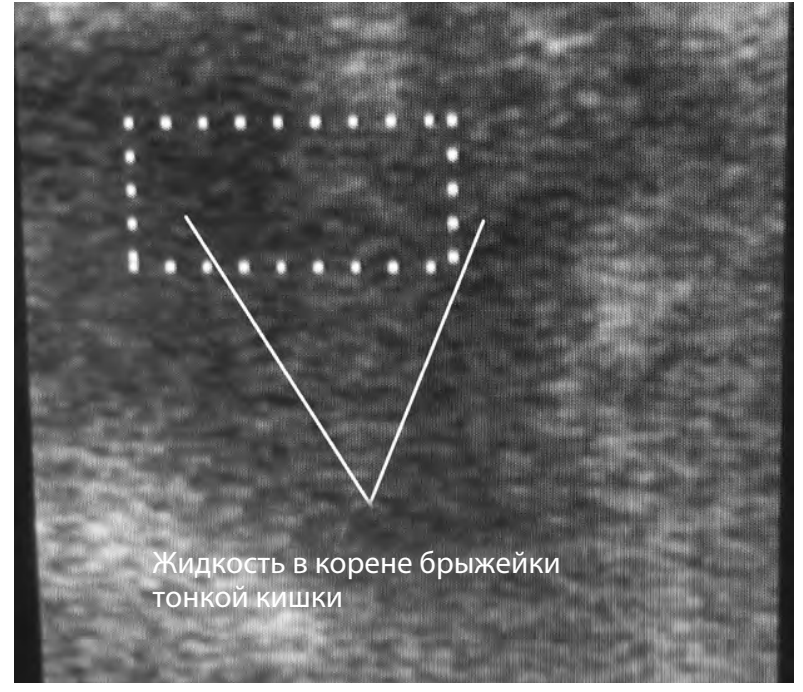

Б

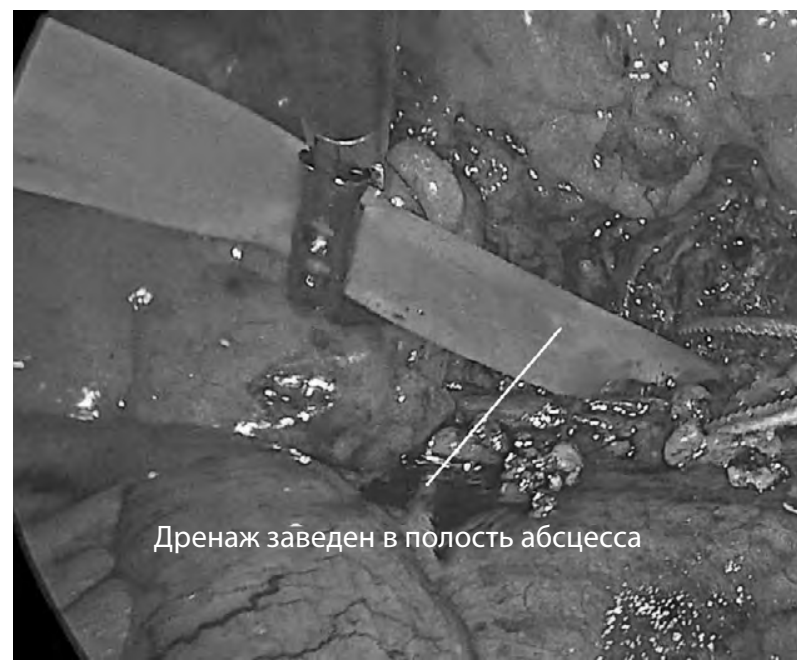

厂

Рис. 7. Этапы операции лапароскопического дренирования абсцесса корня брыжейки тонкой кишки (33-и сут болезни). А - вид брыжейки тонкой кишки при лапароскопии; Б - эндосонограмма абсцесса корня брыжейки тонкой кишки; В - абсцесс вскрыт, получен жидкий гной с секвестрами; Г- в полость абсцесса установлен дренаж

скопической санации сальниковой сумки через свищевое отверстие цистогастральный дренаж и свободнолежащий в просвете желудка стент были удалены (рис. 10). При выполнении рентгеноконтрастного исследования выявлено сообщение сальниковой сумки с полостью абсцесса брыжейки тонкой кишки (рис. 11).

В дальнейшем проводились этапные эндоскопические секвестрэктомии на фоне активного промывания полостей абсцесса брыжейки тонкой кишки и сальниковой сумки раствором хлоргекседина через дренажные трубки (рис. 12). Через 6 сут при санационной эндоскопии отмечалось отсутствие тканевого детрита и секвестров, что свидетельствовало о высокой эффективности процедуры. На фоне лечения отмечалась положительная динами- ка в виде нормализации температуры тела и лабораторных показателей.

Через 15 сут после удаления стента, 30.11.2017 г., при КТ выявлено появление жидкостного содержимого в полости сальниковой сумки. При ФГДС обнаружено сужение цистогастрального свищевого хода до 2 мм. С целью обеспечения адекватного дренирования сальниковой сумки 30.11.2017 г. в свищевой ход между желудком и сальниковой сумкой был повторно установлен самораскрывающийся стент-эндопротез для псевдокист диаметром 12 мм.

В результате проведенных оперативных вмешательств и лечебных манипуляций наблюдалась положительная динамика в состоянии больного. На фоне отсутствия жалоб, нормализации темпера- 
туры тела и лабораторных показателей, отсутствия отделяемого по дренажам, полного регресса жидкостных образований в брюшной полости, а также воспалительных изменений в парапанкреатической клетчатке по данным УЗИ и КТ 15.12.2017 г. при рентгенографии органов брюшной полости выявлена миграция стента в тонкую кишку на расстояние около 100 см от связки Трейца (рис. 13 А).

С учетом отсутствия клинической картины кишечной непроходимости было принято решение о динамическом наблюдении за больным с ежедневными рентгеновскими исследованиями живота. В течение 5 сут продвижения стента по кишке не отмечалось. В связи с неизменным положением инородного тела больному показано оперативное лечение. 21.12.2017 г. выполнена лапароскопия, при которой выявлен выраженный спаечный процесс в верхнем этаже брюшной полости, конгломерат петель тонкой кишки вокруг дренажной трубки, установленной в полость абсцесса брыжейки тонкой кишки. При интраоперационной ревизии и рентгеноскопическом контроле установлено, что стент находится в одной из петель тонкой кишки, вовлеченных в спаечный конгломерат вокруг дренажа абсцесса корня брыжейки тонкой кишки. Разделение спаек лапароскопическим способом не представлялось возможным, в связи с чем была выполнена лапаротомия. При разделении спаек и мобилизации петель тонкой кишки выявлено, что стент фиксирован к воспалительно-измененным стенкам кишки. Выполнена резекция участка тощей кишки с инородным телом с наложением анастомоза конец в конец (рис. 12 Б-Г).

Послеоперационный период протекал гладко, рана зажила первичным натяжением. Больной выписан на 14-е сут после операции в удовлетворительном состоянии.

Схема консервативного лечения больного М. кратко представлена в табл. 1.

Представленное клиническое наблюдение, с одной стороны, демонстрирует эффективность современных хирургических методов в лечении инфекционных осложнений тяжелого панкреатита, с другой - показывает возможные осложнения и трудности, которые могут возникать на различных этапах лечения больных с применением миниинвазивных методик.

Таблица 1

Схема консервативного лечения больного М.

\begin{tabular}{|c|c|c|c|}
\hline Фаза заболевания & Сроки заболевания & $\begin{array}{l}\text { Инфузионная } \\
\text { терапия }\end{array}$ & Антибактериальная терапия \\
\hline І А фаза & 1-8-е сут болезни & $\begin{array}{l}\text { До } 4000 \text { мл/сут, включая синте- } \\
\text { тические аналоги саматостати- } \\
\text { на, антикоагулянты и дезагре- } \\
\text { ганты, спазмолитики. }\end{array}$ & $\begin{array}{l}\text { Антибактериальная профилакти- } \\
\text { ка: Цефалоспорины III поколения } \\
\text { (Цефтриаксон } 4 \text { гр/сут) Метрони- } \\
\text { дазол 1,5 гр/сут. }\end{array}$ \\
\hline І Б фаза & 8-14-е сут болезни & $\begin{array}{l}\text { Продолжена базисная консер- } \\
\text { вативная терапия с постепен- } \\
\text { ным уменьшением объема } \\
\text { инфузии до } 1500 \text { мл/сут }\end{array}$ & $\begin{array}{l}\text { Продолжена антибактериальная } \\
\text { профилактика по прежней схеме }\end{array}$ \\
\hline $\begin{array}{l}\text { II фаза (дренирование } \\
\text { ОЖС сальниковой сумки) }\end{array}$ & 14-33-и сут болезни & До 1000-1500 мл/сут & $\begin{array}{l}\text { Смена антибактериальной } \\
\text { терапии: } \\
\text { Меронем } 3 \text { г/сут в монорежиме. }\end{array}$ \\
\hline $\begin{array}{l}\text { II фаза (вскрытие и } \\
\text { дренирование абсцесса } \\
\text { забрюшинной клетчатки } \\
\text { в области корня брыжей- } \\
\text { ки тонкой кишки) }\end{array}$ & 33-56-е сут болезни & До 1600-2000 мл/сут & $\begin{array}{l}\text { Смена антибактериальной тера- } \\
\text { пии с учетом данных бактериоло- } \\
\text { гического исследования: } \\
\text { Ванкомицин } 2 \text { гр/сут в моноре- } \\
\text { жиме. }\end{array}$ \\
\hline ІІ фаза & 56-91-е сут болезни & \multicolumn{2}{|c|}{$\begin{array}{l}\text { Отмена инфузионной и интибактериальной терапии на фоне норма- } \\
\text { лизации состояния больного }\end{array}$} \\
\hline $\begin{array}{l}\text { Удаление инородного } \\
\text { тела (стента) тонкой } \\
\text { кишки }\end{array}$ & 91-100-е сут болезни & До 1000-1600 мл/сут & $\begin{array}{l}\text { Антибактериалная терапия: } \\
\text { Меронем } 3 \text { г/сут в монорежиме. }\end{array}$ \\
\hline Реконвалесценция & 100-106-е сут болезни & \multicolumn{2}{|c|}{$\begin{array}{l}\text { Отмена инфузионной и интибактериальной терапии на фоне норма- } \\
\text { лизации состояния больного. Выписка больного из стационара на } \\
\text { 106-е сут лечения }\end{array}$} \\
\hline
\end{tabular}




\section{CLINICAL MEDICINE}

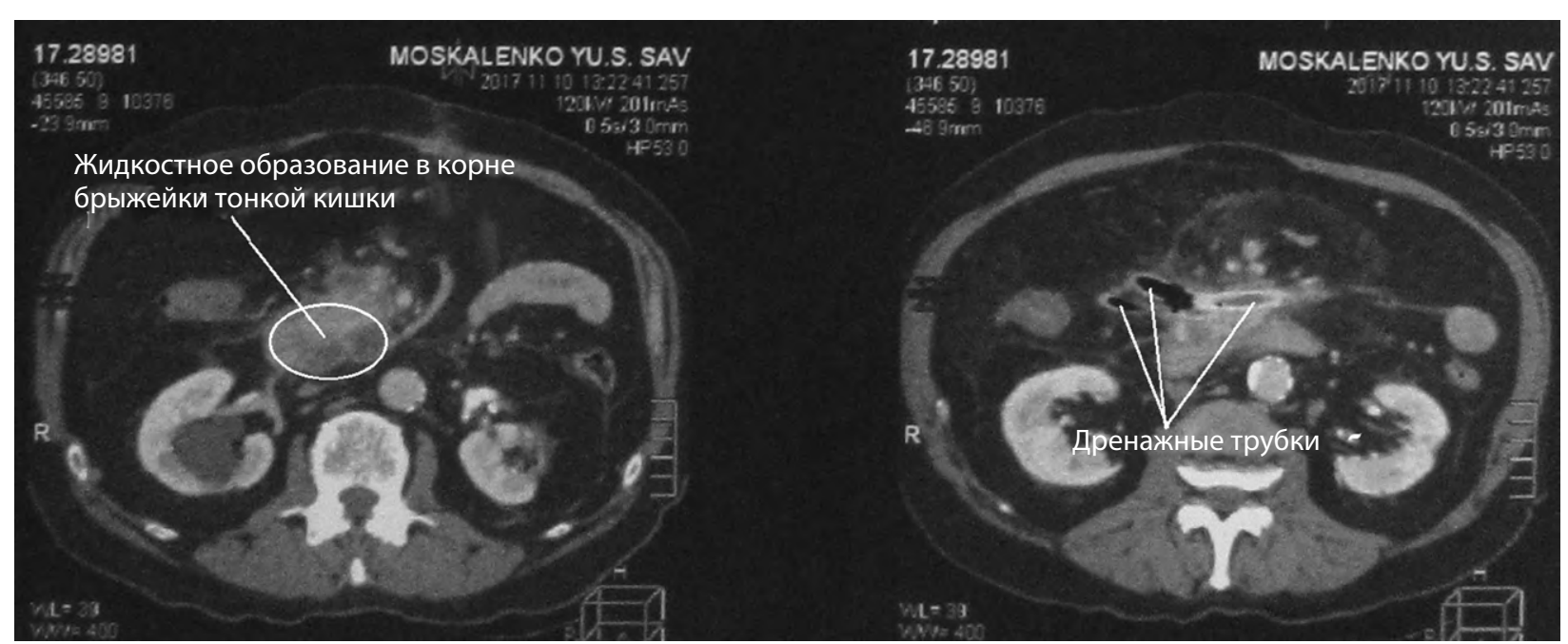

Рис. 8. КТ брюшной полости больного М. от 10.11.2017 г. (51-е сут болезни)

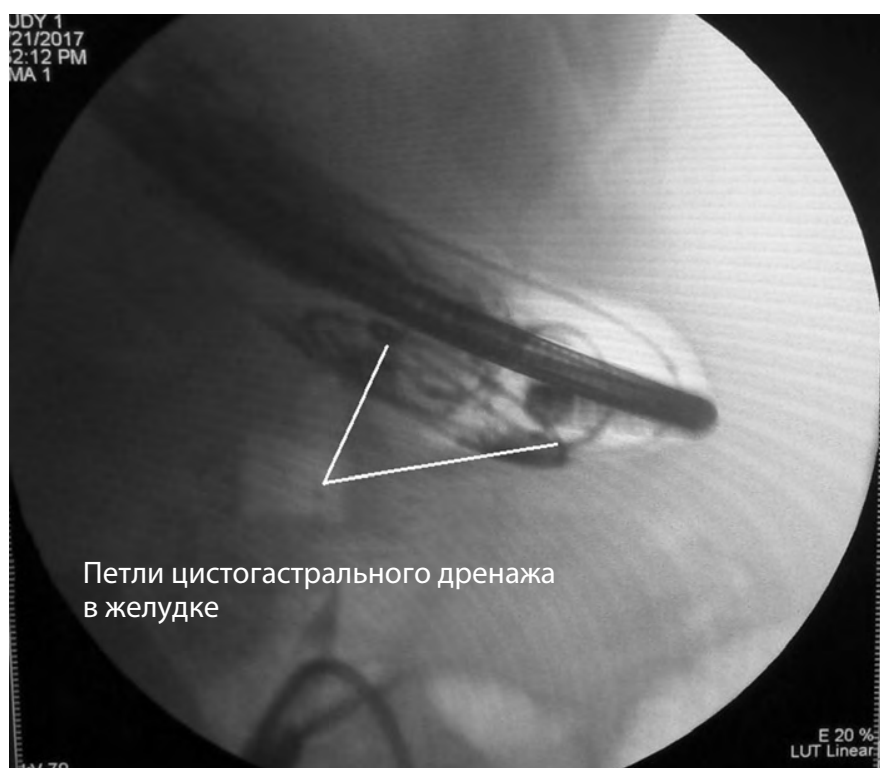

A

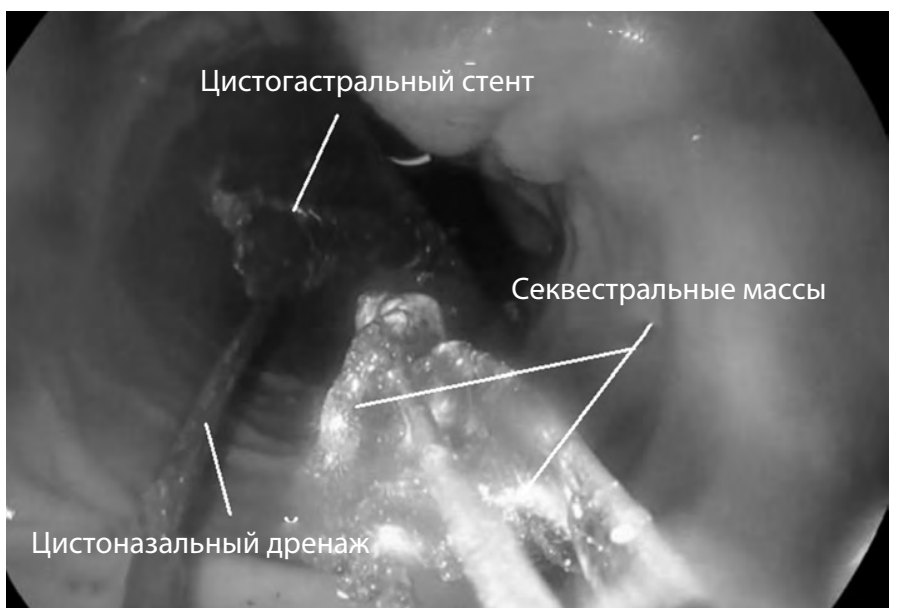

Б

Рис. 9. Рентгенологическое и эндоскопическое исследования на 56-е сут болезни. А 一 рентгенограмма - эндоскоп и петли цистоназального дренажа в желудке; Б - эндоскопическая картина полости желудка 


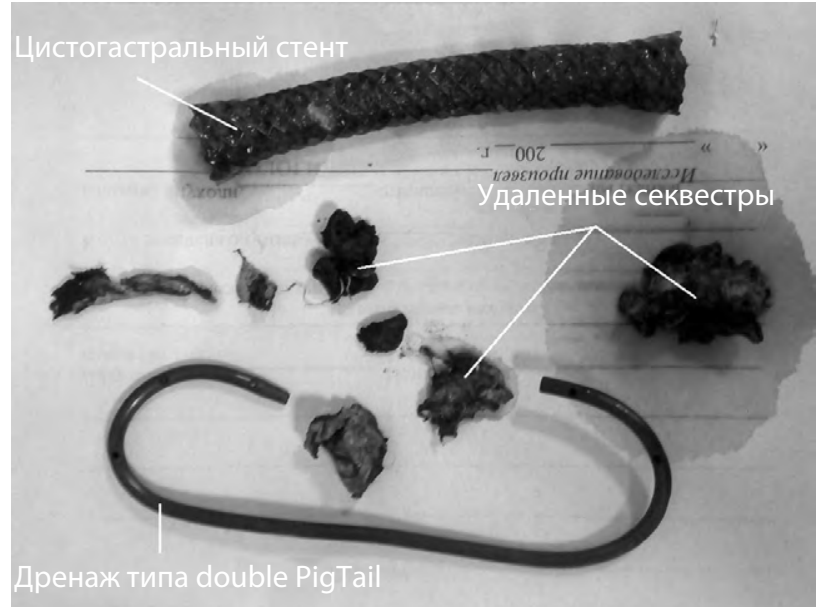

Рис. 10. Удаленные из желудка цистогастральный стент, дренаж типа «double Pig-Tail», секвестры

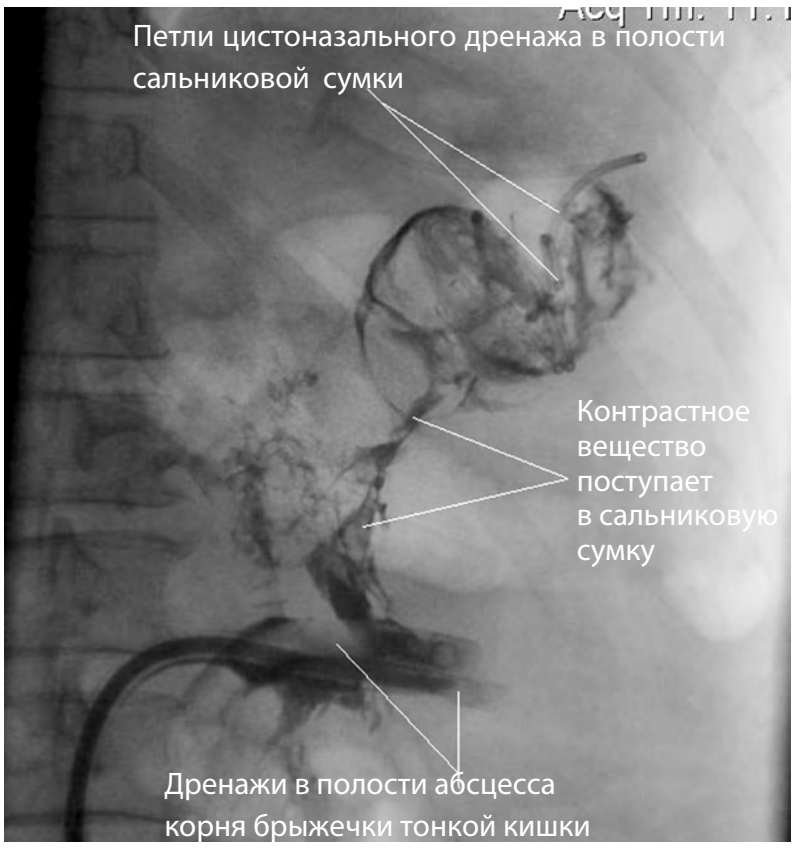

A

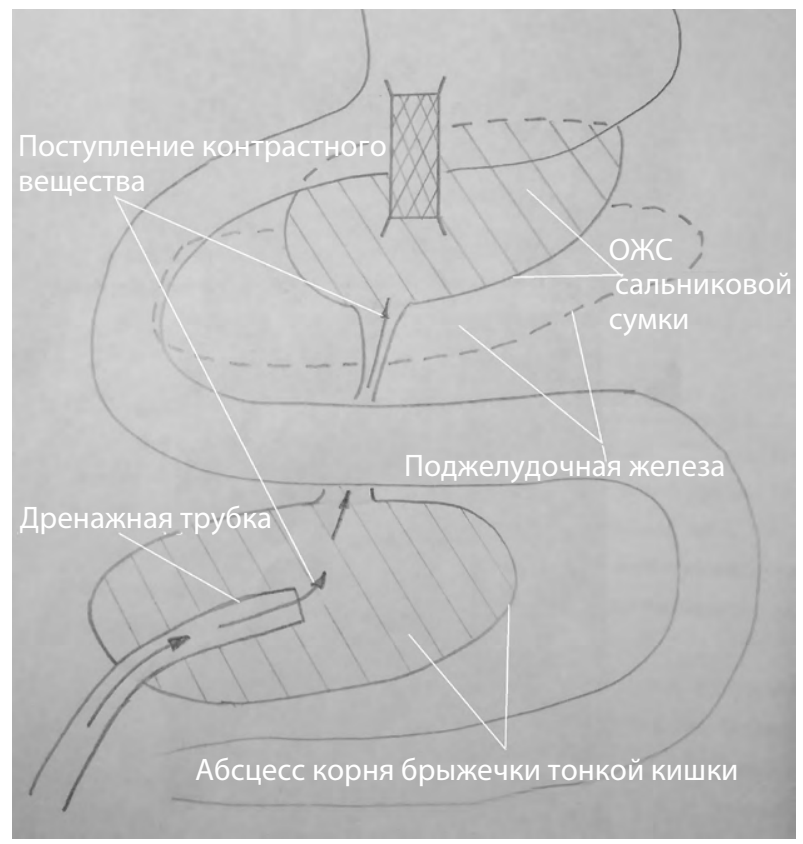

Б

Рис. 11. Контрольное рентгеноконтрастное исследование на 56-е сут болезни. А — рентгенофистулография; Б - схема сообщения полостей

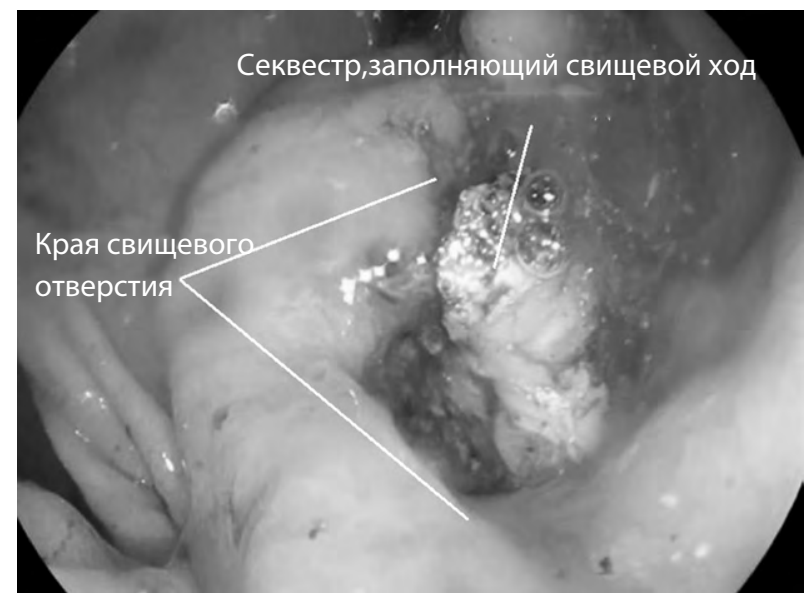

Рис. 12. Эндоскопическая картина при плановой санационной эндоскопии на 56-е сут болезни 


\section{CLINICAL MEDICINE}

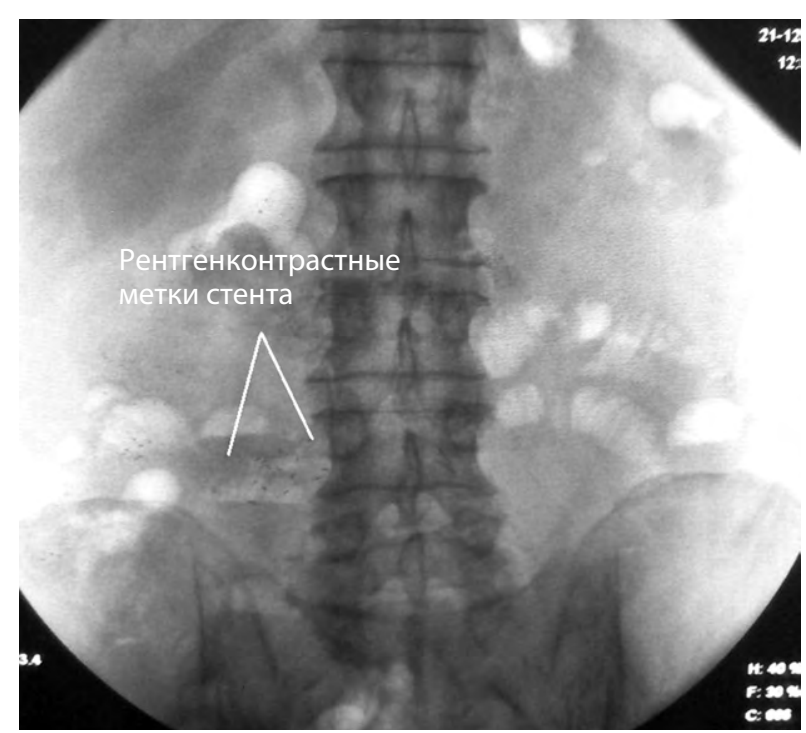

A

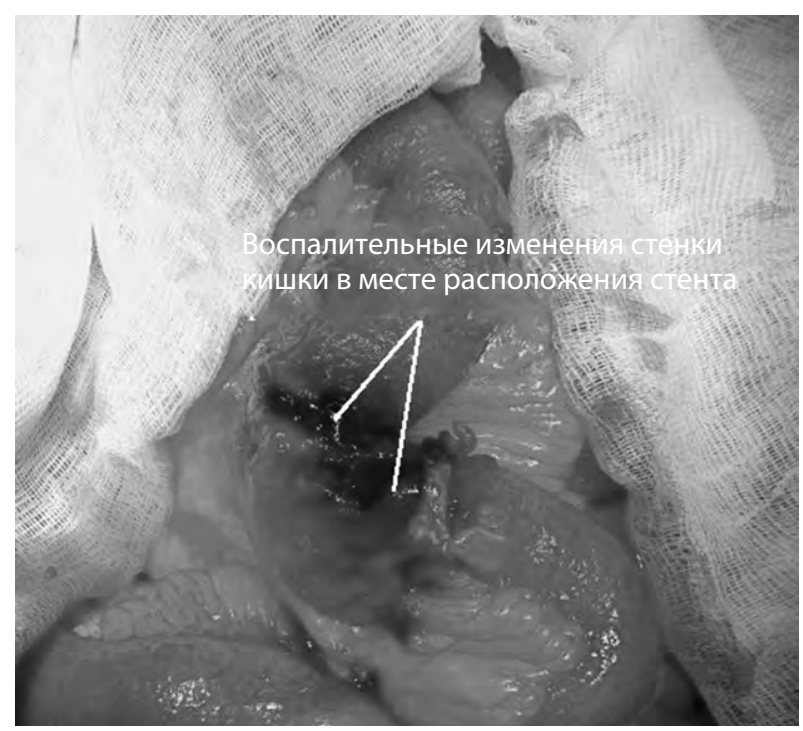

Б

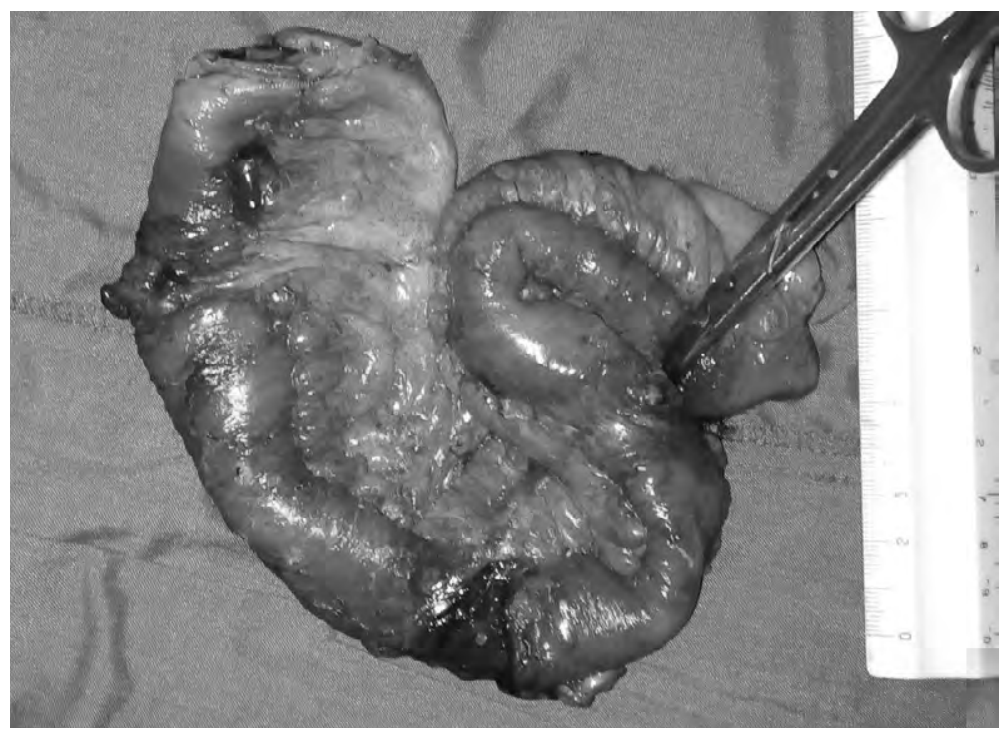

B

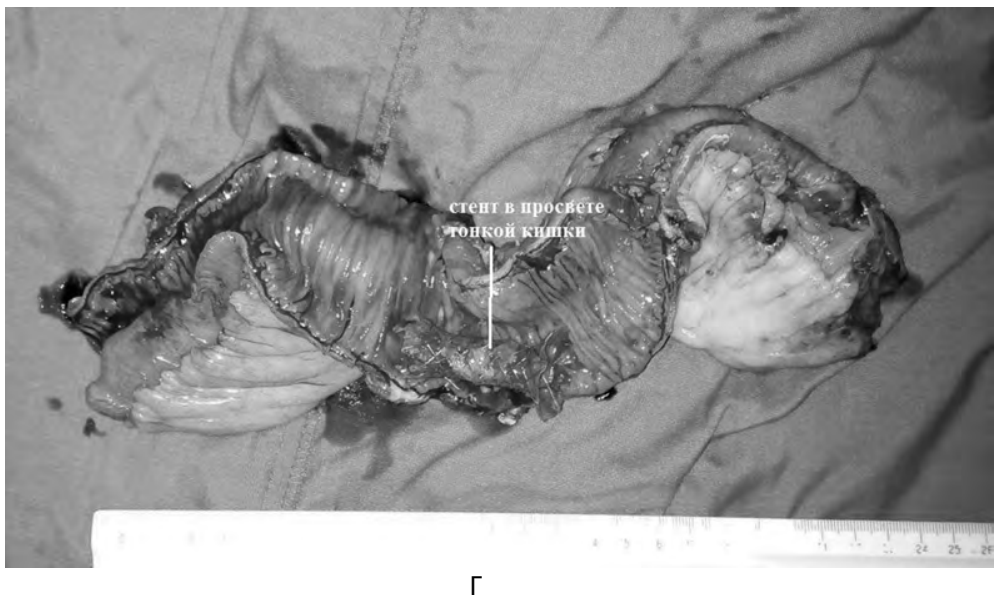

Рис. 13. Этапы операции по удалению стента из просвета тонкой кишки (91-е сут болезни). А - рентгенограмма органов брюшной полости, на которой в проекции тонкой кишки определяется стент; Б - воспалительный инфильтрат и петля тонкой кишки в месте расположения стента; В - макропрепарат удаленной петли тонкой кишки;

$Г$ - удаленный участок тонкой кишки на разрезе, в просвете цистогастральный стент 


\section{УВЕДОМЛЕНИЕ}

Авторы внесли равный вклад в данную работу и сообщают об отсутствии какого-либо конфликта интересов.

\section{СПИСОК ЛИТЕРАТУРЫ / REFERENCES}

1. Yermolov A. S., Ivanov P. A., Blagovestnov D. A., Grishin A. A. Diagnosis and treatment of acute pancreatitis. Moscow: VIDAR-M Publisher; 2013. 384. Russian (Ермолов А. С., Иванов П. А., Благовестнов Д. А., Гришин А. А. Диагностика и лечение острого панкреатита. М.: ВИДАР-М; 2013. 384).

2. Mizgirev D. V., Duberman B. L., Epshteyn A. M., Kremlev V. V., Bobovnik S. V., Pozdeev V. N., Prudiyeva E. V. Complications and lethality in minimally invasive treatment of acute necrotic pancreatitis. Annaly khirurgicheskoy gepatologii. 2014; 19 (2): 66-71. Russian (Мизгирев Д. В., Дуберман Б. Л., Эпитейн А. М., Кремлев В. В., Бобовник С. В., Поздеев В. Н., Прудиева Е. В. Осложнения и летальность при мини-инвазивном лечении острого некротического панкреатита. Анналы хирургической гепатологии. 2014; 19 (2): 66-71).

3. Walchinskaya A. B., Sinenchenko G. I., Goltsov V. R. International experience of the use of antibiotic prophylaxis of

\section{СВЕДЕНИЯ ОБ АВТОРАХ}

Ивануса Сергей Ярославович - докт. мед. наук, професcop, начальник кафедры общей хирургии, ФГБВОУ ВО «Военномедицинская академия имени С. М. Кирова» МО РФ, 194044 Россия, г. Санкт-Петербург, ул. Академика Лебедева, д. 6

Лазуткин Максим Витальевич - докт. мед. наук, заместитель начальника кафедры общей хирургии, ФГБВОУ ВО «Военно-медицинская академия имени С. М. Кирова» МО РФ, 194044, Россия, г. Санкт-Петербург, ул. Академика Лебедева, д. 6

Шершень Дмитрий Павлович - канд. мед. наук, старший преподаватель кафедры общей хирургии, ФГБВОУ ВО «Военномедицинская академия имени С. М. Кирова» МО РФ, 194044, Россия, г. Санкт-Петербург, ул. Академика Лебедева, д. 6

Чеботарь Антон Викторович - майор медицинской службы, курсовой офицер-преподаватель 2 факультета, ФГБВОУ ВО «Военно-медицинская академия имени С. М. Кирова» МО РФ, 194044, Россия, г. Санкт-Петербург, ул. Академика Лебедева, д. 6

\section{ACKNOWLEDGMENT}

Authors contributed equally into this work and declare no conflict of interest.

infectious complications in acute pancreatitis in emergency hospitals. Skoraya meditsinskaya pomoshch. 2017; 18 (1): 39-44. Russian (Вальчинская А. Б., Синенченко Г. И., Гольчов В. Р. Международный опыт применения антибиотикопрофилактики инфекционных осложнений при остром панкреатите в стационарах скорой помощи. Скорая медицинская помощь. 2017; 18 (1): 39-44).

4. Mantke R. International Practices in Pancreatic Surgery. Heidelberg: Springer; 2013. 206.

5. Mowery N. T., Bruns B. R., MacNew H. G., Agarwal S., Enniss T. M., Khan M., Guo W. A., Cannon J. W., Lissauer M. E., Duane T. M., Hildreth A. N., Pappas P. A., Gries L. M., Kaiser M., Robinson B. R. H. Surgical management of pancreatic necrosis: A practice management guideline from the Eastern Association for the Surgery of Trauma. J. Trauma Acute Care Surg. 2017; 83 (2): 316-27.

\section{INFORMATION ABOUT AUTHORS}

Ivanusa Sergey Ya. - M. D., D. Sc. (Medicine), Professor, the Head of the General Surgery Department, S. M. Kirov Military Medical Academy of the Russian Defense Ministry, bld. 6, Akademika Lebedeva str., Saint Petersburg, Russia, 194044

Lazutkin Maksim V. - M. D., D. Sc. (Medicine), Deputy Head of the General Surgery Department, S. M. Kirov Military Medical Academy of the Russian Defense Ministry, bld. 6, Akademika Lebedeva str., Saint Petersburg, Russia, 194044

Shershen Dmitriy P. - M. D., Ph. D. (Medicine), Senior Lecturer of the General Surgery Department, S. M. Kirov Military Medical Academy of the Russian Defense Ministry, bld. 6, Akademika Lebedeva str., Saint Petersburg, Russia, 194044

Chebotar Anton V. - Major of Medical Service, teacher of the $2^{\text {nd }}$ faculty, S. M. Kirov Military Medical Academy of the Russian Defense Ministry, bld. 6, Akademika Lebedeva str., Saint Petersburg, Russia, 194044 